\title{
El sudoeste de la Península Ibérica
}

\section{The Southwest of the Iberian peninsula}

\author{
Eugenio R. Luján \\ Universidad Complutense de Madrid \\ erlujan@ucm.es
}

Resumen: Las inscripciones del Sudoeste de la península ibérica (a las que también se suele hacer referencia como "tartesias") constituyen un conjunto epigráfico de unas cien inscripciones de la Edad del Hierro. Muy probablemente se trata de estelas funerarias en su casi totalidad, escritas en una lengua no identificada. En este trabajo se presenta el estado actual de nuestros conocimientos sobre estas inscripciones y su lengua y se plantean las principales perspectivas desde las que avanzar en la investigación en los próximos años.

Palabras clave: Estelas del sudoeste. Lenguas paleohispánicas. Escrituras paleohispánicas. Edad del Hierro. Tarteso.

Abstract: The Southwestern inscriptions from the Iberian Peninsula (frequently referred to as "Tartessian") are a set of about 100 inscriptions dating back to the Iron Age. Probably most of them are funerary steles, which were written in a language that has not yet been identified. This paper provides a state-of-the-art of our current knowledge about these inscriptions and their language and offers prospectives and insights into the possibilities of the research for further advancing in our knowledge of these inscriptions in the near future.

Keywords: Southwestern steles. Palaeohispanic languages. Palaeohispanic scripts. Iron Age. Tartessos.

Recepción: 13.03.2020 | Aceptación: 25.03.2020

Financiación: Este trabajo es resultado del proyecto de investigación "Estudios de morfosintaxis nominal: lenguas paleohispánicas e indoeuropeas antiguas" (FFI201563981-C3-2), financiado por el Ministerio de Economía y Competitividad del Gobierno de España. Ha sido realizado dentro de las actividades del Grupo de Investigación Consolidado de la Universidad Complutense de Madrid "Textos epigráficos antiguos de la península Ibérica y del Mediterráneo griego". 


\section{1. ¿Qué sabemos sobre la lengua y la escritura de las estelas del Sudoeste?}

\subsection{Informaciones generales}

Mediante la denominación de "estelas del sudoeste" se hace referencia habitualmente a un grupo de en torno a un centenar de inscripciones aparecidas en el suroeste de la península ibérica (sur de Portugal y las vecinas regiones españolas de Andalucía y Extremadura) que en su práctica totalidad constituyen un grupo homogéneo por el tipo de soporte epigráfico $(\$ 1.5)$, las características de la escritura utilizada $(\$ 1.6)$ y también, en la medida en que podemos identificar algunas secuencias dentro de ellas, por la lengua en la que están escritas $(\$ 1.4) .{ }^{1} \mathrm{El}$ término "inscripciones del sudoeste" es un término neutro y descriptivo en relación con la distribución geográfica principal de estas inscripciones $(\$ 1.2)$, que no conlleva implicaciones culturales y de adscripción, aspectos estos que, como iremos viendo, constituyen un problema en sí en el estudio de esta epigrafía. ${ }^{2}$

También es corriente referirse a estas inscripciones como "tartesias", continuando el término utilizado por A. Schulten 1940, en relación con una de las más importantes culturas protohistóricas del área meridional de la península ibérica. Esta es la denominación preferida por J. Untermann en el corpus de referencia para estas inscripciones, el vol. IV de los $M L H .{ }^{3}$ Sin embargo, como veremos un poco más abajo $(\$ 1.2)$, el área de dispersión de las inscripciones no se corresponde con la zona nuclear de dicha cultura. ${ }^{4}$

1 Para cada inscripción que mencionamos en este trabajo damos la referencia tanto a $M L H$ IV como al Banco de Datos Hesperia.

2 Esta es la denominación utilizada habitualmente por J. de Hoz en sus trabajos. J. A. Correa utilizaba la denominación "tartesias" en sus primeros trabajos sobre estas inscripciones y en los últimos tiende a referirse a ellas tanto como inscripciones del SO como tartesias.

3 En cambio, De Hoz 2010, 517-524, reserva la denominación de "escritura tartesia" para una escritura aún no aislada en la Baja Andalucía que constituiría la escritura paleohispánica más antigua de la que, a su vez, derivaría la escritura del SO.

4 A pesar de que es un término en desuso en la investigación actual, conviene recordar aquí que Gómez Moreno se refería a esta escritura como "bástulo-turdetana" (véase especialmente Gómez Moreno 1962). Schmoll 1961 prefería el término "sudlusitano", empleado también en varios trabajos por Rodríguez Ramos, en la combinación "sudlusitano-tartesias" (Rodríguez Ramos 2000; 2002; 2015). 
En este sentido, no sabemos quiénes eran los hablantes de la lengua en la que están escritas estas inscripciones. ${ }^{5}$ Las fuentes clásicas proporcionan los nombres de varios pueblos en el Algarve y zonas aledañas, como los conios o los cinetes, de los que la información de que disponemos no es realmente cuantiosa. A ellos hay que sumar el ya referido nombre de Tarteso, el importante reino de cuya riqueza y elevada cultura nos dan cumplida cuenta las fuentes griegas, así como el de los turdetanos, habitualmente considerados los continuadores de los tartesios en época posterior. ${ }^{6}$ Sin embargo, por razones cronológicas y geográficas no podemos estar seguros de la atribución. Además, nuestras severas limitaciones en el conocimiento de esa lengua $(\$ 1.4)$ nos impiden partir de una adscripción lingüística clara para intentar establecer una vinculación entre pueblos de la zona y hablantes de la lengua en la que está escrito este conjunto de inscripciones.

En este sentido, aunque en los últimos tiempos ha habido varios intentos de identificar la lengua de estas inscripciones como una lengua celta, especialmente por parte de Koch, ${ }^{7}$ pero también más recientemente de Kaufmann 2015, el análisis interno detallado de la lengua de las inscripciones no parece apuntar realmente en esa dirección, como tendremos ocasión de ver más en detalle posteriormente $(\$ 1.4)$. Parece que nos encontramos, más bien, ante una lengua no indoeuropea, que desde el punto de vista tipológico probablemente era de tipo aglutinante, como el ibérico o el etrusco. ${ }^{8}$

La información sobre la lengua de estas inscripciones solo puede verse ampliada, hoy por hoy, en muy escasa medida por algunos datos onomásticos, ya que en algunos casos secuencias que pueden identificarse dentro de las inscripciones y para las que, por su posición dentro de la inscripción, cabe suponer que se trata de nombres personales, encuentran paralelos en

$5 \quad$ Para las informaciones etnográficas transmitidas por los autores antiguos sobre esta región y su relación con las lenguas y la epigrafía de la zona, véase Untermann, $M L H \mathrm{IV}$, 121-125, y la extensa y documentada exposición de De Hoz 2010, 217-353.

6 Sobre la identificación de la lengua de los turdetanos pueden verse muy provechosamente las consideraciones de De Hoz 2019, con referencias a la bibliografía anterior, muy especialmente De Hoz 2010, passim.

7 Son ya muchos los trabajos que ha dedicado J. Koch a este tema. La exposición más amplia y detallada puede encontrarse en Koch 2013.

8 Para una comparación tipológica de estas dos lenguas véase el trabajo de De Hoz 2001. Los datos de la lengua de las estelas del SO son tan escasos y problemáticos que, como veremos más abajo $(\$ 1.4)$, ni siquiera permiten alcanzar conclusiones tipológicas detalladas como las que pueden obtenerse para lenguas con corpus mucho más amplios como el ibérico o, todavía más, el etrusco. 
inscripciones latinas de la misma área o de áreas próximas. ${ }^{9}$ Igualmente, cabe suponer que algunos de los pocos topónimos de la zona transmitidos por las fuentes griegas y latinas deben haber sido acuñados en la misma lengua que las estelas del SO, pero, una vez más, carecemos de criterios claros para poder identificar con seguridad cuáles son, dado que no podemos detectar en ellos morfemas o rasgos lingüísticos compartidos con la lengua de las estelas.

La lengua de las inscripciones del SO ha debido estar en contacto con otras lenguas de la zona. Hay que mencionar, en primer lugar, las lenguas coloniales, de entrada el fenicio, de la que cada vez hay una mayor documentación en esta área, no ya solo de forma general en el sur de la península ibérica, con yacimientos tan importantes en la bahía de Cádiz como el del Cerro de Doña Blanca o la propia ciudad de Gadir (Cádiz), ${ }^{10}$ sino incluso en el actual territorio de Portugal. Recordemos a este respecto el reciente hallazgo de una inscripción funeraria fenicia en Lisboa, datable en el siglo VII a. C. (Neto et al.2016), que podemos considerar un testimonio claro de la navegación atlántica de este pueblo. Por otra parte, la propia escritura del SO no deja de ser una adaptación de la escritura fenicia, ${ }^{11}$ tal y como se pone de manifiesto en las propias formas de los signos de la escritura si se comparan con la escritura fenicia. Lo que ya no podemos afirmar de una forma tajante es si la primera adaptación de la escritura fenicia fue precisamente la escritura del $\mathrm{SO}^{12}$ o bien esta depende de unos primeros intentos de uso con los que estarían vinculados algunos grafitos del sur de la península ibérica ${ }^{13} \mathrm{y}$, notablemente, el signario de Espanca, un documento excepcional que consta de dos líneas con los mismos signos repetidos en ambas: la primera línea tiene mejor trazo y factura y la segunda copia la primera con peor calidad, en lo

9 Sobre la onomástica personal y los nombres de lugar que es posible relacionar con las inscripciones del SO véase el resumen de Correa y Guerra 2019, 137. A propósito de los antropónimos podrá encontrarse información exhaustiva y más detallada en el interesante trabajo de Vallejo, e. p.

10 Yacimientos sobre cuya epigrafía remitimos a Zamora 2019, 57-59.

11 Se ha discutido si, además, de la escritura fenicia, también la escritura griega habría tenido un papel en la creación de la primera escritura paleohispánica, tal y como defendía J. Untermann (véase, por ejemplo, $M L H$ IV 139). Sin embargo, hoy en día la práctica totalidad de los especialistas acepta que el origen de las escrituras paleohispánicas puede explicarse bien a partir únicamente de modelos fenicios; véase, entre otros, Correa 1989b y, sobre todo, De Hoz 2010, 485-517, con referencias a trabajos anteriores.

12 Tal y como defiende Rodríguez Ramos 2000. Véase una revisión crítica de las diferentes posturas en el trabajo de Ferrer y Moncunill 2019, 106-108.

13 Sobre los que puede verse De Hoz 2010, 485-524, con discusión y referencias a la bibliografía anterior. 
que cabe interpretar como un ejercicio de escritura. ${ }^{14} \mathrm{El}$ orden de los signos en esta inscripción permite delimitar un primer conjunto que, aunque con saltos, respeta el orden habitual de las letras fenicias y, podemos suponer, también básicamente su valor fonético. A continuación, tras la wau, viene un segundo grupo de signos, también de origen fenicio pero que se aleja del orden habitual, en lo que parece constituir un reaprovechamiento de las letras pero con un valor fonético diferente al que tienen en la escritura fenicia. Finalmente, se incorpora un tercer grupo de signos que no se encuentran en la escritura fenicia, pero en algunos casos sí en las inscripciones del SO, es decir, un grupo de signos complementarios creados ex novo. Los signos de escritura que se documentan en el signario de Espanca no se corresponden al cien por cien con los empleados en las inscripciones del SO y, por eso, quizá se trate de un intento de adaptación previo a la consolidación del sistema de escritura de las inscripciones del SO.

También hay que contar con la posibilidad de un contacto con otra lengua, el griego, pues es antigua la presencia de griegos en el sur de la península ibérica y comenzamos a tener algunos grafitos en esa lengua ya desde el siglo VII a. C. ${ }^{15}$ Las fuentes antiguas hacen referencia a la presencia de pueblos celtas en el suroeste de la península ibérica, mencionados ya por Heródoto (2.23) y denominados habitualmente Celtici en las fuentes de época romana. De hecho, dentro de las propias inscripciones del SO parecen documentarse algunos nombres personales celtas, como aip ${ }^{\mathrm{u} u r i s,}$ si es que se trata de un compuesto en -rix, ${ }^{16}$ que encontraría un paralelo en el nombre del mítico rey de Tarteso Gárgoris, ${ }^{17}$ o también $\mathbf{t}^{\mathrm{i} i r \mathbf{t}^{\mathbf{0}}}{ }^{\mathrm{os}}$, entre otros que se han señalado en

14 Un análisis paleográfico pormenorizado se encuentra en Correa 1993. Véase también el estudio de De Hoz 2010, 488-516, y la edición de Untermann, MLH IV, 327-329 (J.25.1).

15 Véase De Hoz 2010, 436-455, para el análisis de los datos sobre la lengua griega en el sur de la península ibérica.

16 Como sugirió Correa 1985, 393.

17 En cambio, hay que desterrar la idea de que en el inicio de la estela de Fonte Velha,

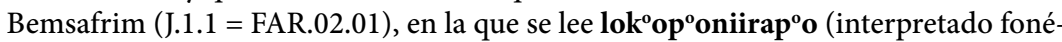
ticamente como logobo nirabo), se encuentre una referencia al dios celta Lug en una forma de dativo plural en -obo, seguida de un epíteto en concordancia vinculado con la raíz indoeuropea ${ }^{\star} h_{2} n e r$ - 'fuerte' ( $c f$. gr. ảvń $\rho$, lat. Nero, etc.). Correa 1981, 208-209, identificó esta secuencia, que podría analizarse como un posible elemento celta dentro de las inscripciones del SO, y Untermann, $M L H$ IV, 166-167, indica el paralelo de lok on dentro de la misma inscripción. Lamentablemente, otros autores han aceptado esta mera posibilidad de una forma acrítica. En mi opinión (Luján, e. p.), el análisis interno de las inscripciones nos permite constatar que -nii es frecuente en final absoluto de las inscripciones, como en el frecuentísimo naŕk ${ }^{e}$ enii (véase $\$ 1.4$ ) y, además, las otras dos 
la bibliografía ( $\$ 1.7)$. Además, los hablantes de la lengua del SO han debido estar en contacto con otras lenguas indígenas de la zona, con el tartesio (si es que no era la misma lengua) y con las lenguas de otros pueblos mencionados por las fuentes, de las que prácticamente nada sabemos. ${ }^{18}$

\subsection{Localización y cronología de las inscripciones}

Las inscripciones del SO se localizan básicamente en un área del sur de Portugal, si bien hay ejemplares también en áreas del sur de España, dentro de las regiones de Andalucía y Extremadura (mapa. 1).

Por lo que se refiere a su cronología, el problema principal es que las estelas no han aparecido en sus contextos originales, por lo que los conjuntos arqueológicos a los que pertenecen proporcionan, en todo caso, una fecha ante quem. Dado que se trata del conjunto epigráfico más antiguo de las escrituras paleohispánicas, la tendencia habitual ha sido a elevar la fecha y llevarla, incluso, al siglo VIII a. C. para la creación del sistema de escritura y la posible datación de alguno de los ejemplares más antiguos. ${ }^{19}$

No obstante, como indican Correa y Guerra 2019, 125, dado que hay un grupo de estelas que corresponden a necrópolis de la Edad de Hierro, fechables entre los siglos VII y V a. C. y con las que pueden ponerse en relación las estelas con inscripciones del SO, resulta verosímil atribuirles las mismas fechas. Combinando esto con algunas dataciones obtenidas por carbono-14 y por los hallazgos asociados, Correa y Guerra 2019, 126, concluyen que el periodo más probable para situar las estelas son los siglos VI-V a. C., Untermann (MLH IV, 135-136) era, incluso, partidario de rebajar esa cronología como mínimo al siglo $\mathrm{V}$ a. C.

apariciones de -onii se encuentran precisamente en final de inscripción, una en la propia inscripción de Fonte Velha (- $\mathbf{t}^{\mathrm{a}}$ asiioonii) y otra en el -eonii de una inscripción de Fonte Velha (J.1.5 = FAR.02.05). Esto apunta, por tanto, a que -onii debe ser final de palabra y, en realidad, el inicio de la inscripción de Fuente Velha probablemente debe segmentarse

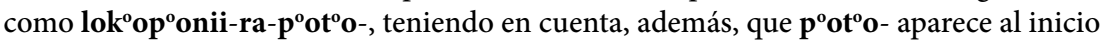
de una inscripción del Vale dos Vermelhos en Loule (J.7.2 = FAR.04.06).

18 Determinar la situación lingüística en el Sur de la península ibérica en la Antigüedad es muy complicado, especialmente debido a la escasez de datos. Contamos ahora con un trabajo reciente de conjunto de De Hoz 2019, al que remitimos. 


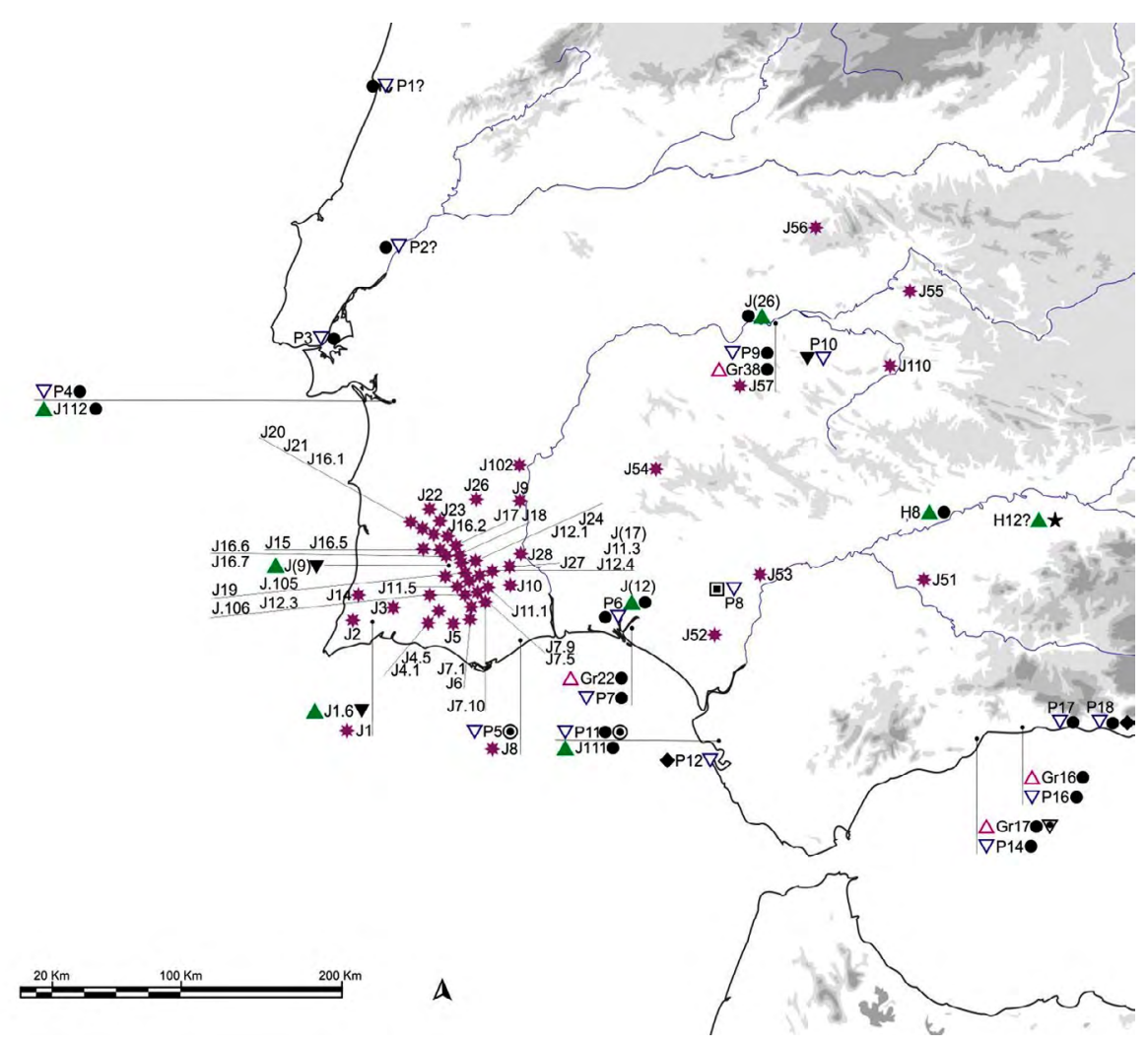

Mapa 1. Inscripciones anteriores al siglo IV a. C. en el sudoeste de la península ibérica, con los lugares de hallazgo de las inscripciones del SO representados por círculos morados. Realizado por Javier de Hoz y Daniel Romero dentro del proyecto Hesperia.

\subsection{Estudios y ediciones de las inscripciones ${ }^{20}$}

La primera recopilación importante de estas inscripciones fue llevada a cabo a finales del siglo XVIII por Fray Manuel do Cenáculo, quien en el conocido como Album de Cenáculo, ${ }^{21}$ documentó un conjunto importante de inscripciones del SO, muchas de ellas hoy en día perdidas y para cuyo estudio dependemos de esta fuente. El siguiente hito importante para su estudio son los Monumenta Linguae Ibericae de Emil Hübner de 1893, quien añadió algunos ejemplares más.

A lo largo del siglo XX siguieron apareciendo nuevas estelas con inscripciones tanto en Portugal como en el sur de España y hubo varias recopilacio-

20 Para la historia de la investigación sobre estas inscripciones véase Untermann, $M L H$ IV, 114-120.

21 Conservado en la Biblioteca Pública de Évora, códice CXXIX. 
nes por parte de Gómez Moreno 1962, Schmoll 1961 y Maluquer de Motes 1968, si bien habría que esperar hasta los trabajos de Caetano de Mello Beirâo y, especialmente, a la publicación del catálogo de estelas que apareció como tercer volumen de su obra Une civilization proto-historique du Sud de Portugal de 1986 para tener un corpus completo de relevancia.

Ya del último decenio del siglo XX contamos con dos corpus de referencia de las inscripciones, publicados prácticamente al mismo tiempo, que son los de Correia 1996 y Untermann, en el volumen IV de sus Monumenta Linguarum Hispanicarum, del año 1997. Conviene manejarlos de forma conjunta, ya que se encuentran diferencias entre las lecturas de uno y otro autor y, además, dado que no pudieron hacer uso mutuo de las informaciones por elaborarse simultáneamente, no se encuentran en ellos referencias cruzadas. También hay que señalar la memoria de licenciatura inédita de Rodríguez Ramos del año 1992, que contiene un estudio exhaustivo de este conjunto de inscripciones. $^{22}$

En la actualidad, dentro del Banco de Datos Hesperia ${ }^{23}$ se ha incluido ya una ficha para cada una de las inscripciones del SO conocidas en la actualidad, tanto las que ya figuraban en los corpus de Correia y Untermann como las publicadas con posterioridad. ${ }^{24}$ La parte relativa a las inscripciones del SO dentro del Banco de Datos todavía no está abierta para su consulta pública, pero está previsto que pueda estarlo en un plazo breve de tiempo.

Por lo que se refiere a los estudios de conjunto sobre estas inscripciones, además de los que acompañan a los corpus y recopilaciones ya mencionados, hay que mencionar el tratamiento extenso que hace de este conjunto de inscripciones y de su escritura y su lengua Javier de Hoz 2010, 354-484, dentro del primer volumen de su enciclopédica Historia lingüística de la península Ibérica en la Antigüedad, así como en numerosos trabajos de J. A. Correa que se mencionan a lo largo del trabajo y recogemos en la bibliografía final.

22 Aunque la memoria en sí quedó inédita, Rodríguez Ramos ha dedicado a este conjunto de inscripciones y, especialmente, al estudio de su escritura diversos trabajos: Rodríguez Ramos 2000; 2002; 2015.

23 Disponible en $<$ http://hesperia.ucm.es $>$.

24 Dentro de la revista Palaeohispanica se publica una "Crónica epigráfica del Sudoeste" a cargo de J. A. Correa, en la que se recogen las novedades sobre estas inscripciones. Hasta el momento ha habido cinco entregas: Correa 2002; 2004; 2006; 2008; 2016. 


\subsection{La lengua de las inscripciones del SO}

El conocimiento que tenemos de la lengua de las estelas del SO es muy limitado, y esto por varias razones. En primer lugar, se debe al tipo de textos con los que contamos, que, como venimos viendo, son inscripciones funerarias, lo que reduce enormemente el léxico y los elementos gramaticales que resulta esperable que aparezcan. Como también corresponde al tipo epigráfico, se trata de inscripciones breves. De hecho, la inscripción más larga que conocemos hoy en día es la de Mesas do Castelinho (BEJ.06.13), publicada por Guerra 2009, 325-329, con algo más de ochenta caracteres originalmente. Además de esto tenemos el problema de que no podemos considerar la escritura totalmente descifrada, a pesar de que haya acuerdo en la interpretación fonética de una parte importante de los signos ( $\$ 1.6)$. Todo esto hace que sea muy poco lo que podemos afirmar con seguridad acerca de la lengua de las inscripciones del SO.

Con todas las cautelas debidas, intentamos sistematizar algunos de los rasgos de esta lengua. ${ }^{25}$ Parece que nos encontramos ante una lengua que diferencia cinco timbres vocálicos: /a/, /e/, /i/, /o/, /u/. Por lo que se refiere a las secuencias de dos signos vocálicos, se documentan como diptongos decrecientes ai, ei, oi, ui (dudoso), au (poco frecuente), eu (probablemente inexistente), iu, ou (probablemente inexistente); como diptongos crecientes, ia, ie, io, ua (probablemente no diptongo, sino secuencia fonética [wa]), mientras que ue no existe y solo hay dos secuencias uo.

En cuanto a las oclusivas, parece evidente que la lengua de las estelas tenía, al menos, consonantes labiales, dentales y velares, pero el problema radica en la imposibilidad de determinar si había o no varios modos de articulación $(\$ 1.6)$. Es posible que hubiera consonantes oclusivas con un cuarto punto de articulación (véase $\$ 2.1$ ). En estrecha relación con la interpretación de los signos de la escritura, podemos contar con que la lengua tenía con seguridad una nasal $/ \mathrm{n} /$ y quizá también $/ \mathrm{m} /$. Tenía, igualmente, dos silbantes (sin que podamos entrar a precisar más su definición fonética), una lateral /1/ y, probablemente, también dos vibrantes (véase $\$ 1.6$ ).

25 Las principales descripciones detalladas de esta lengua que se pueden manejar hoy en día son MLH IV, 156-168; De Hoz 2010, 386-402; Correa y Guerra 2019, 128-136. Por razones de espacio, en la discusión que sigue no entramos por lo general en el detalle de las posturas de cada autor, sino que proporcionamos la información que, a nuestro juicio, es más segura o probable. 
Como en toda lengua, estos fonemas se combinaban en sílabas que, siguiendo a De Hoz 2010, 388-389, podían ser de los siguientes tipos: ${ }^{26} \mathrm{~V}$, VR, CV, CVR; son dudosos (C)VRN y (C)VRS. Y subsiste el problema de los onsets o ataques silábicos complejos tipo CRV en relación con la inadecuación del semisilabario para la escritura de este tipo de secuencias (\$1.6).

Si nos movemos más allá del plano fonético y fonológico e intentamos adentrarnos en la gramática y el léxico de la lengua, para evitar caer en arbitrariedades y wishful thinking, tenemos que operar con puntos de partida claros que nos permitan detectar, por un lado, repeticiones de secuencias que lleven a identificar elementos gramaticales o léxicos e, igualmente, sus variaciones. Para ello resulta razonable apoyarse en los siguientes pilares:

- la fórmula funeraria -naŕke- y sus combinaciones,

- "palabras" o secuencias repetidas en posiciones similares,

- identificación de elementos en posición final o "desinencias",

- identificación de posibles nombres propios.

Todos los autores que han trabajado sobre estas inscripciones coinciden en aislar una secuencia -naŕk $\mathbf{e}^{\mathrm{e}}$-, que aparece muy frecuentemente en las inscripciones y debe ser un componente básico de la fórmula funeraria de esta lengua. La existencia de las formas -naŕk ${ }^{\mathbf{e}} \mathbf{t}^{\mathrm{i}} \mathbf{i}\left(\mathrm{J} .56 .1=\right.$ CC.05.01) y -naŕk $\mathbf{e}^{\mathbf{e}} \mathbf{e n t}^{\mathrm{i}} \mathbf{i}$ (J.12.1 = BEJ.06.06; J.16.1 = BEJ.04.01; J.16.3 = BEJ.04.03; J.17.2 = BEJ.04.09) ha creado el espejismo de que podemos encontrarnos ante una lengua indoeuropea con desinencias temáticas -eti y -enti de, respectivamente, 3. ${ }^{a}$ persona de singular y de plural del presente. Sin embargo, como bien indican Correa y Guerra 2019, 135-136, si esto fuera así, no se entiende por qué, en secuencias que parecen paralelas, integradas probablemente por un antropónimo y

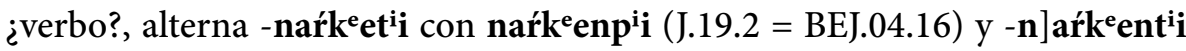
(J.1.5 = FAR.02.05). Además, si se presta atención al conjunto de las "desinencias" con las que aparece "conjugada" la base -naŕkee-, tenemos, entre otras, las formas naŕk ${ }^{\mathbf{e}} \mathbf{e n a i}{ }^{27}$ naŕk $\left.^{\mathbf{e}} \mathbf{e n i i}^{28} \mathbf{o}\right]$ naŕk $\mathbf{k}^{\mathbf{e}} \mathbf{e u u}+\left[{ }^{29}\right.$ que resultan mucho más difíciles de reducir a la morfología verbal de una lengua indoeuropea, a no ser

$26 \mathrm{~V}=$ vocal $\mathrm{C}=$ consonante; $\mathrm{R}=$ líquida o lateral $\mathrm{y}$, en la coda, también nasal.

27 Documentada en las inscripciones J.7.1 = FAR.04.05 y J.55.1 = BA.04.01.

28 En J.1.2 = FAR.02.02; J.2.1 = FAR.01.01; J.7.10 = FAR.04.14; J.21.1 = BEJ.04.19; J.22.1 = BEJ.04.20. A las que probablemente haya que sumar, nŕk enii $(J .11 .1=$ BEJ.06.01) y ]aŕk enii (J.11.3 = BEJ.06.03).

29 En la inscripción publicada por Guerra 2002, 228-229 (BEJ.06.12). 
que, como hace de forma totalmente arbitraria Kaufmann 2015, uno decida que se trata de otro tipo de elementos. ${ }^{30}$

Acompañando a este elemento base -naŕk $k^{\mathbf{e}}$-, pueden aparecer otros elementos adicionales, constituyendo diferentes fórmulas, las cuales, según la clasificación de De Hoz 2010, 389-400 (pero con la transcripción modificada), pueden agruparse en dos tipos: la fórmula breve ( $\left.\mathbf{p}^{\mathrm{a}} \mathbf{a}\right)$ naŕk $^{\mathrm{e}} \mathbf{e}-\mathrm{y}$ la fórmula larga $\left(\mathbf{t}^{\mathrm{e}} \mathbf{e}\right)(\mathbf{e r o}) \mathbf{p}^{\mathrm{a}} \mathbf{a r e}\left(\mathbf{p}^{\mathrm{a}} \mathbf{a}\right)$ naŕk $^{\mathrm{e}} \mathbf{e}$-. No podemos entrar aquí en el análisis de detalle de cada uno de los elementos que integran estas fórmulas, pero estas observaciones sí que pueden servir para presentar el tipo de metodología combinatoria que parece aconsejable aplicar a estos textos en vez de saltar a presentar análisis etimológicos más que especulativos como los que han llevado a Koch 2013 y a Kaufmann 2015 a ver en estas inscripciones una lengua celta, curiosamente sin que haya tampoco entre ellos mismos coincidencias sistemáticas en cuanto a las interpretaciones y explicaciones etimológicas propuestas.

En cambio, la comparación de elementos "afijados" que se repiten sobre bases que también se repiten, permite comenzar a establecer ciertos paradigmas o pautas de variación morfosintáctica, como los que recogemos en el siguiente cuadro:

\begin{tabular}{|c|c|c|c|}
\hline naŕk $\mathrm{e}^{\mathrm{e}}$ & pare & & \\
\hline naŕk ${ }^{\mathrm{e}} \mathrm{en}$ & $\mathrm{p}^{\mathrm{a} a r e n}$ & & \\
\hline naŕk ${ }^{e}$ eii & $\mathrm{p}^{\mathrm{a} a r e i i}$ & - lakeei- (?) & \\
\hline naŕk enii & & & $-+p^{a} \operatorname{rek}^{e}$ eni (?) \\
\hline nark ${ }^{e}$ ent $t^{i} i$ & $\mathrm{p}^{\mathrm{a}} \operatorname{arent}^{\mathrm{t} i}$ & -lakent $\mathrm{t}^{\mathrm{i}}$ & \\
\hline naŕk enai & & & \\
\hline
\end{tabular}

Por lo que se refiere al léxico, por su aparición en varias inscripciones resulta posible identificar algunas secuencias, como uarp ${ }^{\mathrm{a}}$ an y iop $^{\mathrm{a} a}$ (de las que nos ocupamos en $\$ 1.7$ ) o iru. Igualmente, se pueden aislar varios

30 Kaufmann 2015 solo acepta tres formas verbales, que, según su transcripción, son: nazkeentii ( $3 .^{a}$ pl. pres.), nazkeenii ( $3 .{ }^{a}$ pl. impf.), nazkee (3. ${ }^{a}$ sg. impf.). En J.7.1 = FAR.04.05 y J.55.1 = BA.04.01 analiza nar'k ${ }^{\mathrm{e}}$ enai como nazkeen $<\mathbf{n}>\mathbf{a i}$, con na: $\mathbf{i}<$ ${ }^{*}$ sinda:i (dem. sg. fem.) 'para ella'. Y en J.19.1 = BEJ.04.15; J.21.1 = BEJ.04.19, etc. analiza naŕk ${ }^{e}$ enii como nazkeen ii, con i: < ${ }^{*}$ ey-es (pron. 3. ${ }^{\text {a }}$ pl. nom.) 'ellos'. 
"sufijos" que se repiten en las inscripciones. Así, Untermann MLH IV, 161-162, identifica los siguientes: -ea, -ta, -on, -kun, -tero/-ro, -oir, -śe y -ne, sin que estemos seguros del valor o función que hay que atribuirles. La identificación de los sufijos se realiza en casos como el de -ne cuando parece que, efectiva-

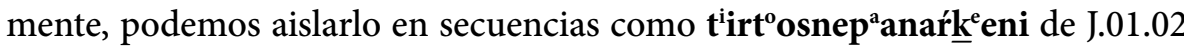
= FAR.02.02, en la que -ne sigue a un probable antropónimo tirt $^{\mathrm{i}} \mathbf{o s}_{\text {(fonética- }}$ mente /tirtos/ o /tritos/) y precede a la fórmula funeraria $\mathbf{p}^{\mathrm{a}}$ anaŕk ${ }^{\mathrm{e}} \mathbf{e n i}$.

\subsection{Tipos de inscripciones}

El grupo de inscripciones a que nos estamos refiriendo constituye per se un grupo homogéneo, caracterizado por el sistema de escritura y por el tipo epigráfico. En principio, la escritura del SO se vincula con un único tipo epigráfico, que es el de las estelas, al que, con la excepción que señalaremos después, pertenecen todas las inscripciones. ${ }^{31}$ Se trata de estelas de piedra de no demasiado grosor, con una función muy probablemente funeraria, pues, si bien estas no han aparecido en su contexto originario, su vinculación con necrópolis hace que podamos suponer que se trata de la reutilización o abandono de antiguas estelas funerarias en ámbitos espaciales con continuidad de uso, ${ }^{32}$ si bien, como recuerdan Correa y Guerra 2019, 114, hay que ser conscientes de que hoy por hoy no podemos asegurar que ninguna de las estelas aparecidas en contextos funerarios sea contemporánea de los enterramientos a los que han aparecido asociadas. La propia disposición del campo epigráfico en las estelas, que en muchísimos casos deja libre de escritura la parte inferior (véanse figs. 1 y 2), invita a pensar que se hincaban en el suelo por esa parte, de tal forma que sobresaliera por encima del suelo el área de la piedra que lleva la inscripción. Esto refuerza la idea de que nos encontremos ante inscripciones funerarias.

Las estelas pueden tener diferentes formas, siendo más o menos alargadas, pero el campo epigráfico presenta típicamente una disposición muy especial y característica de este conjunto epigráfico: frente a las epigrafías contemporáneas del Mediterráneo occidental, en las que las líneas de escritura son habitualmente horizontales, en el caso de las estelas del SO la escritura gira en torno al centro de la piedra, comenzándose normalmente por la parte inferior

31 Para la descripción material de las estelas y su función véase Untermann, $M L H$ IV 130-136.

32 Véase un listado reciente de las estelas asociadas con cementerios de la Primera Edad del Hierro en Correa y Guerra 2019, 114. 
derecha, ya sea en forma de espiral propiamente dicha o bien en rectángulos que se van disponiendo en torno al centro, según nos dejan ver los ejemplares mejor conservados, como el de Fonte Velha, Bensafrim (J.1.1 = FAR.02.01).

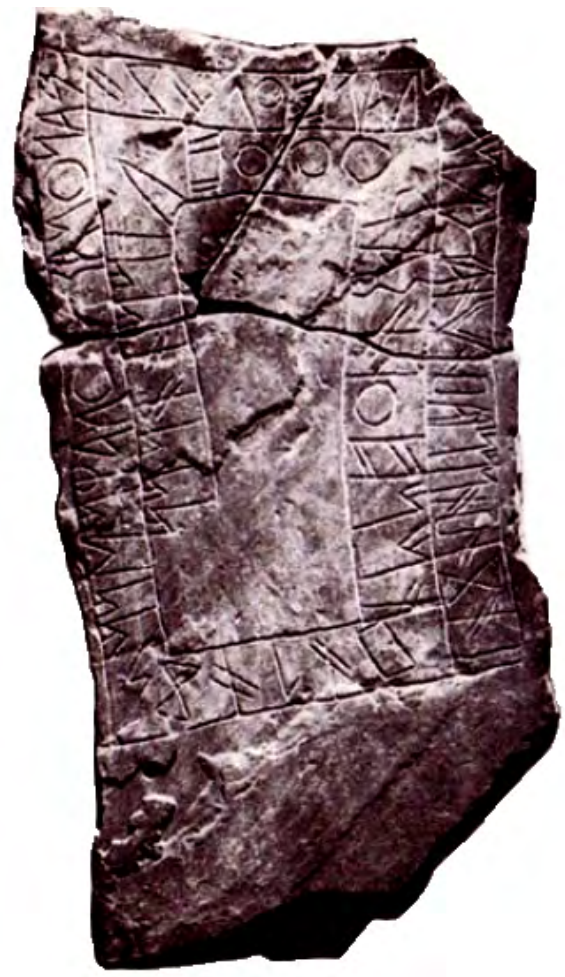

Fig. 1. Estela de Fonte Velha, Bensafrim (J.1.1 = FAR.02.01).

Además, en la mayor parte de las inscripciones (aunque no siempre) la secuencia de signos de escritura queda enmarcada entre dos líneas paralelas. Como decíamos, estas características permiten una clara identificación del tipo epigráfico, a pesar del alto nivel de variabilidad que, como han señalado bien Correa y Guerra 2019, 115, refleja una falta de estandarización de los modelos. La escritura sigue habitualmente una dirección de derecha a izquierda, como sucede ocasionalmente en las otras escrituras paleohispánicas, si bien la disposición de los textos puede hacer que en algunos casos haya líneas que deban leerse de izquierda a derecha. En todo caso, la orientación de los signos coincide con la dirección de la escritura.

Por lo que se refiere al sistema de escritura, como tendremos ocasión de ver un poco más abajo ( $\$ 1.6)$, además de por los signos en sí, la escritura del SO se ha definido por el uso redundante de los signos vocálicos tras los signos 
silábicos que representan la combinación de una consonante y una vocal. Si consideramos que la redundancia es una característica definitoria de este conjunto epigráfico, entonces la única inscripción que podemos clasificar dentro de este grupo y que no puede considerarse una estela funeraria es la placa de esquisto de Folha de Ranjâo en Baleizâo, Serpa (BEJ.02.01), publicada no hace muchos años por Faria, Soares y Soares 2014, de un tamaño de unos pocos centímetros, que no cuadra con el mucho mayor de las estelas y que, además, está escrita por ambas caras. El carácter tan fragmentario del texto impide cualquier posibilidad de interpretación. Sin embargo, la lectura en la cara A de la secuencia $] \mathbf{p}^{\mathbf{o}} \mathbf{o i e k}^{\mathbf{u}} \mathbf{u}$ [, con la redundancia típica de estas inscripciones, obliga a clasificarla dentro del este grupo.

En cambio, si entendemos que la redundancia vocálica no es un rasgo necesario de la escritura para poder agrupar otras inscripciones junto con las que estamos estudiando, el panorama variaría y podríamos vincular con ellas también otros tipos de epígrafes. Sobre esta cuestión véase $\$ 2.2$.

\subsection{La escritura del $\mathrm{SO}^{33}$}

Podemos contar, de entrada, con que, al igual que sucede con todas las escrituras paleohispánicas, nos encontramos ante un semisilabario, es decir, un sistema de escritura en el que coexisten signos silábicos (para escribir la combinación de una consonante oclusiva más vocal) y signos alfabéticos (para las continuantes y las vocales).

Para determinar el valor fonético de los signos de la escritura del SO podemos recurrir a una suma de criterios que permitan establecer valores que, además, deberán ser corroborados por el estudio combinatorio interno de las secuencias que aparecen en las inscripciones. Estos criterios de partida son básicamente dos: a) valor fonético de los signos en la escritura fuente, es decir, en la fenicia, y b) valor fonético de los signos en las otras escrituras de la familia paleohispánica. ${ }^{34}$

33 Como bibliografía de referencia y tratamientos de detalle extensos sobre la escritura del SO hay que mencionar MLH IV, 137-155, y De Hoz 2010, 371-386, además de diversos trabajos de J. A. Correa: 1985; 1987; 1996; 2005 entre otros.

34 También resulta muy relevante para establecer los valores de los signos de la escritura del SO el signario de Espanca, al que ya nos hemos referido $(\$ 1.1)$, tal y como han indicado recientemente Correa y Guerra 2019, 116-119, si bien dicho signario no puede considerarse tal cual el signario SO. 
La escritura del SO presenta, además, otra característica muy significativa que permite comprobar los valores atribuidos a los signos; nos referimos a la "redundancia vocálica", es decir, al hecho de que en esta escritura a los signos silábicos habitualmente les sigue, de forma redundante, el signo para la misma vocal que ya está incluida en el signo silábico, es decir, al signo ta le sigue una a, al signo ke una e, etc. ${ }^{35}$

A partir de estas combinaciones de criterios se puede llegar a determinar de forma bastante segura el valor fonético de un buen número de signos de la escritura del SO, en los que hay acuerdo entre los investigadores, según se pone de manifiesto en la Tabla 1, tomada de MLH IV, 153. Como puede verse, existe consenso generalizado sobre un buen número de silabogramas (no así sobre los signos con los posibles valores po, pu, ko, ku y también pi), sobre todos los signos vocálicos y los signos para la lateral, las silbantes y una de las vibrantes, pero subsisten dudas acerca del valor fonético de algunos signos, alguno de ellos tan frecuentes como el signo con dos cuernos (S56), que la mayoría de los investigadores interpreta como una segunda vibrante (transcrita como ŕ), pero De Hoz 2010, 380, considera de valor incierto y transcribe habitualmente como W. Tampoco es segura la existencia de un segundo signo para otra nasal $/ \mathrm{m} /$. Especial dificultad plantean los signos en forma de escale$\mathrm{ra}^{36}$ sin que podamos estar totalmente seguros de cuáles son signos diferentes y cuáles son simples alógrafos. Igualmente, hay un número de signos menos frecuentes (véanse tablas 1 y 2), cuya escasa frecuencia de aparición (a veces, incluso, son hápax), imposibilita esclarecer su valor fonético.

35 Es mérito de Schmoll 1961 haber descubierto este hecho.

36 Correa 2005, 298, n. 16, denominó "escalares" a estos signos en forma de H con múltiples trazos horizontales y que, en último término, deben derivar de la heth fenicia. Son transcritos por De Hoz precisamente como $\mathbf{H}$ por la forma que tienen (para su análisis, véase De Hoz 2010, 377-379). 
MLH VHC. RR. Correa de Hoz Mal. Schm. GM.

\begin{tabular}{|c|c|c|c|c|c|c|c|c|}
\hline A & a & a & a & a & a & $a$ & a & a \\
\hline 0 & $\mathrm{e}$ & $\mathrm{e}$ & $\mathrm{e}$ & $\mathrm{e}$ & $\mathrm{e}$ & ku & e & o \\
\hline v & $\mathrm{i}$ & $\mathrm{i}$ & $\mathrm{i}$ & $\mathrm{i}$ & $\mathrm{i}$ & $\mathrm{i}$ & $\mathrm{i}$ & $\mathrm{i}$ \\
\hline$\neq$ & o & $\mathrm{e} / \mathrm{o}$ & $\mathrm{o} / \mathrm{u}$ & o & o & $\mathrm{e}$ & o & $\mathrm{e}$ \\
\hline 4 & $\mathbf{u}$ & $\mathbf{u}$ & $\mathbf{u}$ & $\mathrm{u}$ & $\mathrm{u}$ & o & $\mathrm{u}$ & $\mathrm{u}$ \\
\hline 1 & 1 & 1 & 1 & 1 & 1 & 1 & 1 & 1 \\
\hline 4 & $\mathrm{n}$ & $\mathrm{n}$ & $\mathrm{n}$ & $\mathrm{n}$ & $\mathrm{n}$ & $\mathrm{n}$ & $\mathrm{n}$ & $\mathrm{n}$ \\
\hline$M$ & $\mathrm{~m}$ & & ś? & $-^{u}$ & & $\mathrm{~m}$ & & \\
\hline 9 & $\mathbf{r}$ & $\mathbf{r}$ & $\mathrm{r}$ & $\mathrm{r}$ & $\mathrm{r}$ & $\mathrm{r}$ & $\mathrm{r}$ & $\mathbf{r}$ \\
\hline$r$ & r & $\mathrm{m}$ & $\dot{\mathbf{r}}$ & ŕ & bi? & be & & be \\
\hline 丰 & $s$ & $s$ & $s$ & $s$ & $s$ & $s$ & $s$ & $s$ \\
\hline$M$ & ś & $s$ & ś & ś & ś & ś & ś & $s$ \\
\hline 3 & $b^{a}$ & $\mathrm{pa}$ & ba & $\mathrm{P}^{\mathrm{a}}$ & ba & $s$ & & $\mathrm{~m}$ \\
\hline 9 & $b^{e}$ & pe & be & $\mathrm{P}^{\mathrm{e}}$ & be & & & \\
\hline $\mathrm{\square}$ & $b^{o}$ & $\mathrm{po} / \mathrm{pu}$ & bo & $\mathrm{P}^{\mathrm{o}}$ & bu & $\mathrm{bu}$ & po & bu \\
\hline$\Delta A$ & $b^{u}$ & ko & $\mathrm{ku}$ & $\mathrm{P}^{\mathrm{u}}$ & bo & & $\mathrm{pu}$ & bo \\
\hline$\wedge$ & $\mathrm{k}^{\mathrm{a}}$ & $\mathrm{ka}$ & $\mathrm{ka}$ & $\mathrm{K}^{\mathrm{a}}$ & ka & $\mathrm{ka}$ & $\mathrm{ka}$ & $\mathrm{ka}$ \\
\hline$>1$ & $\mathrm{k}^{\mathrm{e}}$ & ke & ke & $\mathrm{K}^{\mathrm{e}}$ & $\mathrm{ke}$ & ke & $\mathrm{ke}$ & ke \\
\hline $\mathrm{Z}$ & $\mathrm{k}^{\mathrm{o}}$ & ko & ko & $\mathrm{K}^{\mathrm{o}}$ & ko & ko & ko & ko \\
\hline 目 & $\mathrm{k}^{\mathrm{u}}$ & & ta & $\mathrm{K}^{\mathrm{u}}$ & & to & $\mathrm{h}$ & $\mathrm{ti}$ \\
\hline$x$ & $t^{a}$ & ta & $\mathrm{ta}$ & $\mathrm{T}^{\mathrm{a}}$ & $\mathrm{ta}$ & ta & ta & ta \\
\hline H & $\mathrm{t}^{\mathrm{e}}$ & & & $\mathrm{T}^{\mathrm{e}}$ & te & to & $\mathrm{h}$ & $\mathrm{ti}$ \\
\hline (1) & $\mathrm{t}^{\mathrm{i}}$ & ti & ti & $\mathrm{T}^{\mathrm{i}}$ & $\mathrm{ti}$ & te & ti & te \\
\hline$\Delta$ & $t^{o}$ & to $/ \mathrm{tu}$ & to & $\mathrm{T}^{\mathrm{o}}$ & & tu & to & tu \\
\hline$\Delta$ & $t^{u}$ & to $/ \mathrm{tu}$ & $\mathrm{tu}$ & $\mathrm{T}^{\mathrm{u}}$ & $\mathrm{tu}$ & to & tu & $\mathrm{tu}$ \\
\hline$\Phi$ & $-{ }^{\mathrm{i}}$ & ki & ki & $\mathrm{K}^{\mathrm{i}}$ & ki & $\mathbf{r}$ & pi & $\mathrm{ku}$ \\
\hline$\uparrow$ & $-{ }^{\mathrm{i}}$ & & bi & & ti & $\mathrm{u}$ & tu & $\mathbf{u}$ \\
\hline$E$ & $-{ }^{a}$ & & & $--^{a}$ & & $\mathrm{ti}$ & & to \\
\hline
\end{tabular}

Tabla 1. Valores de los signos de la escritura del SO según diferentes autores (tomado de $M L H$ IV, 153). MLH = MLH IV, VHC. $=$ Correia 1996, RR. = Rodríguez Ramos 1992, Correa $=$ Correa 1996, de Hoz $=$ De Hoz 1990, Mal. $=$ Maluquer de Motes 1968, Schm. $=$ Schmoll 1961, GM. = Gómez Moreno 1962. 
$\mathrm{Al}$ igual que en el resto de las escrituras paleohispánicas, ${ }^{37}$ los signos silábicos para las oclusivas solo diferencian puntos de articulación, es decir, no se representa gráficamente la oposición sorda/sonora, por lo que el signo que convencionalmente transcribimos como ta puede ser fonéticamente / ta/o /da/. En el caso de la escritura del SO no parece que se emplearan marcas diacríticas que permitan diferenciar modos de articulación para las consonantes del mismo punto de articulación. ${ }^{38}$ No hay una forma directa de escribir los grupos consonánticos, por lo que, si existían en la lengua de las estelas (véase $\$ 1.4$ ), debía recurrirse a alguno(s) de los procedimientos que encontramos en las otras lenguas paleohispánicas. ${ }^{39}$

Las inscripciones están habitualmente en scriptio continua, si bien en algunas de ellas aparecen trazos verticales que parecen funcionar como separadores de "palabras" o unidades lingüísticas.

\subsection{Onomástica personal y fórmulas onomásticas}

Dado el carácter verosímilmente funerario de las estelas del SO, resulta esperable que se documenten en ellas nombres personales, de acuerdo con lo habitual para este tipo epigráfico en la Antigüedad y, específicamente, en la cultura fenicia que, en último término, es la cultura epigráfica a partir de la cual surge el hábito epigráfico en el SO peninsular teniendo en cuenta que la escritura del SO deriva de una adaptación de la escritura fenicia.

En diferentes trabajos ${ }^{40}$ Correa ha propuesto identificar como nombres personales secuencias como aip ${ }^{\mathrm{u}} u r i s, t^{\mathrm{u}} u$ uraio (o $\mathbf{t}^{\mathrm{u}} \mathbf{u r k}^{\mathrm{a}}$ aio), akosioś, uursaar (o uulsaar), ainest $^{\mathrm{a}} \mathrm{a}$, ooŕoir, soloir. El punto de partida para estas identificaciones son inscripciones breves como J.56.1 = CC.05.01, en la que se lee:

37 Contamos ahora con la existencia de signarios "duales" en ibérico (y posiblemente también otras variedades de escrituras paleohispánicas), pero, en todo caso, los signos para sordas y sonoras de las escrituras paleohispánicas siempre son el mismo signo base con la diferencia de una marca diacrítica adicional para diferenciar uno de ellos, concretamente el sordo en el caso de la escritura ibérica noroccidental (véase ahora la presentación de conjunto de Ferrer y Moncunill 2019, 82-89 y 93-97, con las referencias a los trabajos anteriores).

38 Sobre esta cuestión véase en último lugar Ferrer 2016, 68-70.

39 Es decir, cabrían teóricamente estas tres posibilidades: a) no escribir uno de los signos del grupo [ta $\mathbf{t}^{\mathrm{a}}$ por /tra/]; b) escribir el segundo signo tras la vocal [tar ar por/tra/], o c) repetir el signo vocálico [ $\mathbf{t}^{\mathrm{a}}$ ara por / tra/], si bien esta última posibilidad parece menos probable por la propia dinámica de este silabario y el uso redundante de las vocales. 


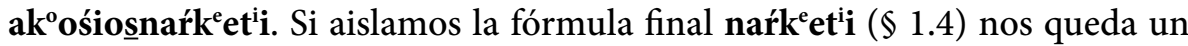
elemento ak $\mathbf{k}^{\mathbf{0}} \mathbf{s}$ ios, que es muy probable que sea un antropónimo. ${ }^{41}$

También se ha pretendido identificar como nombres femeninos algunas secuencias en -ea, como saruneea o nemunt urea. El primero cuenta con buenos pararalelos en la onomástica indígena peninsular, ${ }^{42}$ pero en el caso de nemunt "urea, aceptado por Untermann $M L H$ IV, 160-161, no vemos ninguna razón dentro de la inscripción para no aislar mejor - $\mathbf{t}^{\mathrm{u}} \mathbf{u r e a}$, que sí que cuenta con paralelos en la epigrafía latina de Portugal.$^{43}$ En todo caso, aun con todas las inseguridades que tenemos en el análisis de estas inscripciones, da la impresión de que tanto hombres como mujeres se identifican con nombres individuales únicos.

Es preciso señalar que se han aislado algunos elementos que se combinan con secuencias identificadas como antropónimos. Tal es el caso de uarpaan, que aparece al menos en seis ocasiones y que Correa 1992, 101, interpretó como /warman/, procedente etimológicamente de celta ${ }^{*}$ uperamos, $c f$. celtib. ueramos, es decir, como un título o cargo institucional (¿magistrado?) con el significado de "el más alto, supremo". Aunque la etimología celta es especulativa y no ha sido aceptada por otros autores, Untermann MLH IV, 160, o De Hoz 2010, 399, n. 399 , sí consideran posible (que no probado) que pueda tratarse de un título. De esta forma, en secuencias como soloiruarpa $\underline{a}$, al inicio de J.11.03 = BEJ.06.03, tendríamos una fórmula onomástica integrada por el nombre personal seguido de este título. Quizá tengamos también un término institucional o un nombre de parentesco que se integra en la fórmula onomástica en la secuencia iopa que sigue al posible nombre personal femenino ] $\mathbf{a n p}^{\mathrm{a}} \mathbf{a t}^{\mathrm{i}} \mathbf{i a}^{44}$ en la inscripción J.16.2 $=$ BEJ.04.02 y, en la variante iup ${ }^{\mathrm{a}} \mathbf{a}$, a nemunt ${ }^{\mathrm{u}}$ urea en J.07.08 $=$ FAR.04.12. ${ }^{45}$

41 En cambio, según la pretendida interpretación celta de Kaufman 2015, el análisis de esta inscripción y su traducción subsiguiente serían:

\begin{tabular}{|c|c|c|}
\hline$a=$ koliyo & $+\$$ & n=a=zgeti \\
\hline ad=kvol.iyo-s & +esti & en=ad=rig/seg-eti \\
\hline $\mathrm{TO}=$ wheel-like-Ns & BE-3sgPRS & $\mathrm{IN}=\mathrm{TO}=$ bind $/$ plant -3 sgPRS \\
\hline
\end{tabular}

42 En formas como gen. [Iu]liu[s] Saronis [CPILC $380=$ HEpOL 15369 (Cáparra CC)], Saronis $[$ HEp 7, 1997, 405ad = HEpOL 6517 (Alcalá de Henares M)] y [P]r(imus) Axonius Saron(is) [HEp 12, 633 = HEpOL 24724 (Borva, Évora)].

43 [T] urea / [A]lbonif(ilia) [AE 1985, 522 = HEpOL 18510 (Vilanova de Foz Coa GUA)], Turea / Paci f(ilia) [RAP $590=$ HEpOL 22167 (Castelo Branco)].

44 Ambatus/- $a$ es uno de los nombres indígenas más frecuentes en las inscripciones del Occidente peninsular ( $c f$. Vallejo 2005, 134-140).

45 No podemos estar seguros de si hay que identificarlo también con el ioua que sigue a 


\section{Problemas actuales y perspectivas de futuro en el estudio de la lengua y la escritura de las estelas del Sudoeste}

\subsection{Problemas y perspectivas en el estudio de la lengua de las estelas del SO}

Dadas las limitaciones para el estudio de la lengua del SO ya mencionadas más arriba $(\$ 1.4)$, no resulta esperable que puedan producirse grandes avances en nuestra comprensión de la lengua en los próximos años, a no ser que tengamos la fortuna de tener nuevos hallazgos realmente excepcionales. Sin embargo, sí que podemos esperar un progreso lento pero seguro en la identificación de características lingüísticas de la lengua de las estelas, basado en un escrutinio detallado de la información que nos proporcionan los textos.

Así, por ejemplo, análisis fonéticos más refinados permiten observar pautas o regularidades no descritas previamente. Una cuestión fonética, pero ligada indisociablemente a un hecho de escritura, que se plantea en las inscripciones es la frecuente aparición de dos signos vocálicos iguales. ${ }^{46}$ Hasta ahora simplemente se había señalado la falta de sistematicidad de este tipo de secuencias, sin que pudiera atribuírseles una causa de aparición. Sin embargo, un estudio de detalle (Luján, e. p.) ha permitido poner de manifiesto que, lejos de ser un fenómeno caótico, pueden observarse regularidades, como el hecho de que las secuencias de vocales posteriores oo y uu, así como la central aa, tiendan claramente a aparecer ante líquidas y vibrantes, mientras que las secuencias de vocales anteriores ee e ii tiendan a encontrarse tras $\mathbf{n}$. Todavía es prematuro intentar dar una explicación a estos hechos en términos gráficos o fonológicos, pero el aparente caos empieza a dejar de ser tal y se abren nuevas vías de trabajo.

Por lo que se refiere a las consonantes oclusivas, más allá de la imposibilidad hoy por hoy de diferenciar oposiciones de modo de articulación para el mismo punto de articulación (\$1.4), el análisis combinatorio exhaustivo realizado por Ferrer 2016, 72-74, parece apuntar a un hecho ya vislumbrado en la bibliografía anterior, como es la posible existencia de una cuarta serie

aark $^{\mathrm{u} u i o r}$ al comienzo de J.07.06 = FAR.04.10, si bien en este caso no hay razones para pensar que se trate de un nombre femenino. 
(no completa) de oclusivas, cuyo valor fonético habrá que intentar precisar en próximos estudios. ${ }^{47}$

Para avanzar en la adecuada segmentación de los textos y en una identificación más precisa de los elementos léxicos y gramaticales, necesariamente habrá que continuar en los próximos años con el análisis de las combinaciones de elementos. Pero, si queremos progresar en nuestra comprensión de la lengua de las estelas, además de aislar elementos, como señalábamos en $\$ 1.4$, habrá que intentar también identificar correlaciones entre elementos que aparecen simultáneamente en la misma inscripción, como sucede con la aparición de formas en -oir con la forma naŕkeeni, que quizá nos permita proponer una posible fórmula -oir ... (uarp $\left.{ }^{\mathrm{a} a n}\right)$... naŕk $\mathrm{e}^{\mathrm{e}} \mathrm{eni}$.

En el terreno de la gramática y de la segmentación de secuencias también está llamado a tener un papel mayor el estudio de la función de los separadores en las inscripciones que los tienen $(\$ 1.6)$ en relación con los elementos que aparecen en posición final en las estelas y las secuencias repetidas y paralelas.

También habrá que profundizar en las vías de investigación más adecuadas para el estudio de la onomástica presente en las inscripciones, aprovechando tanto los posibles paralelos de secuencias en la onomástica indígena de las inscripciones latinas del sur de Portugal y áreas adyacentes, como las posibilidades de segmentación interna de los textos. En este sentido, por ejemplo, en relación con el elemento léxico uarp ${ }^{\mathrm{a}}$ an que hemos mencionado en $₫ 1.4$, hay que interrogarse tanto sobre el valor de la posible variante uarp $^{\circ}$ oiir que puede aislarse en la secuencia uarp ${ }^{\circ}$ oiirsaruneeap ${ }^{\mathrm{a}}$ arenaŕk $^{\mathrm{e}} \mathbf{e n i i}^{\mathrm{i}}$ de la inscripción J.22.1 = BEJ.04.20, ante el posible nombre femenino saruneea que, a su vez, precede a la fórmula funeraria $\mathbf{p}^{\mathrm{a}}$ arenaŕk ${ }^{\mathrm{e}} \mathbf{e n i i}$, como sobre la posible relación con antropónimos como Varbius, atestiguado en una inscripción latina de Lisboa. $^{48}$

Si en la metodología científica se debe evitar de forma general "jumping to conclusions", en el caso de la lengua de las estelas del SO lo que se debe evitar a toda costa es "jumping to translation": la traducción solo puede ser el resultado final de un proceso hermenéutico de interpretación de las inscripciones a partir del análisis interno de los textos y, además, llevando a cabo una aplicación razonable de métodos ensayados con otras lenguas antiguas,

47 Véase también Rodríguez Ramos 2015, con referencias a trabajos anteriores.

48 En la que se lee: $L($ ucius) Varbius $L($ uci) f(ilius) / Gal(eria) Tanginus / $h($ ic) $s($ itus) $e(s t)$ [CIL II $255=$ HEpOL 21308 (Lisboa)]. 
como el de los cuasibilingües, es decir, el recurso a los paralelos de otras epigrafías coetáneas en tipos de textos similares y no inventando nuevos tipos epigráficos no atestiguados en la Antigüedad y que solo existan en la mente del traductor. ${ }^{49}$

Ya hemos comentado $(\$ 1.1)$ que la situación lingüística en el sur de la península ibérica dista mucho de mostrársenos de manera clara en el estado actual de la investigación, por lo que la investigación futura también tendrá que contribuir a precisar las relaciones de la lengua de las estelas del SO con otras lenguas del área y, más allá de esto, en el conjunto de las familias lingüísticas documentadas en el Mediterráneo occidental en la primera Edad del Hierro y con proyección hacia atrás hasta la situación lingüística en el Bronce Reciente.

\subsection{Algunas cuestiones pendientes en el estudio de las inscripciones del SO}

Ya de entrada una cuestión muy interesante es cómo ha surgido un tipo epigráfico tan característico y peculiar como el de las estelas del SO, puesto que, desde luego, la disposición de la escritura en el soporte epigráfico carece por completo de paralelos en la epigrafía fenicia ${ }^{50} \mathrm{y}$ también en la griega. Se suele pensar que el tipo epigráfico responde a dos estímulos a la vez, uno indígena y otro colonial. El colonial sería el propio uso de la escritura, cuya introducción en esta área geográfica responde sin lugar a dudas a una influencia foránea. Sin embargo, el tipo epigráfico en sí debe estar relacionado con tradiciones anteriores: aunque la distribución solo es parcialmente coincidente con la de las estelas del SO, se conoce en época del Bronce Final un tipo de estela de guerrero, con una amplia difusión por la parte sudoccidental de la península ibérica, en la que a la representación esquemática de la figura humana acompaña una serie de elementos de ajuar como carros, espejos, puñales, lanzas y escudos (fig. 3). ${ }^{51}$ La mención del difunto, acompañada de las correspondientes fórmulas funerarias de las inscripciones, habría reemplazado a esa representación iconográfica del guerrero. Además, la propia disposición de las inscripciones

49 Como sucede cuando uno lee las traducciones de Kaufman 2015 y en algunos casos también de Koch 2013.

50 Para las inscripciones funerarias fenicias de la península ibérica véase Zamora 2019, 72-73.

51 La bibliografía sobre las estelas de guerrero es inmensa. Para una revisión de conjunto reciente puede consultarse la tesis doctoral de Díaz-Guardamino 2010, con discusión de los trabajos anteriores. 
podría responder a tipos epigráficos de transición en los que convivieran la imagen y el texto escrito, tal y como sucede en la estela de Abóbada (J.12.1 = BEJ.06.06, fig. 2) o en la mucho más fragmentaria de Benaciate I (J.4.2 = FAR.03.03). Aunque una explicación así parecería razonable, sin embargo, choca de facto con el hecho de que la aparición simultánea en una estela de imagen y escritura sea realmente excepcional, pues, como decíamos en $₫ 1.1$, conocemos hoy en día en torno a cien inscripciones del SO y solo dos de ellas presentan figuración. Y, además, en los dos casos, por razones paleográficas e iconográficas parece tratarse de estelas más bien tardías (Correia 1996, 27-28). El surgimiento del tipo epigráfico es, por tanto, un campo en el que habrá que seguir investigando.

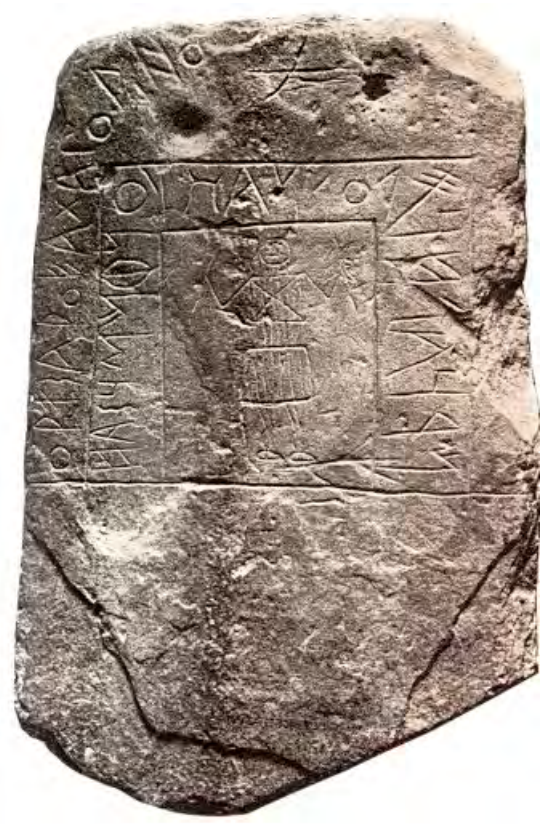

Fig 2. Estela de Abóbada (J.12.1 = BEJ.06.06).

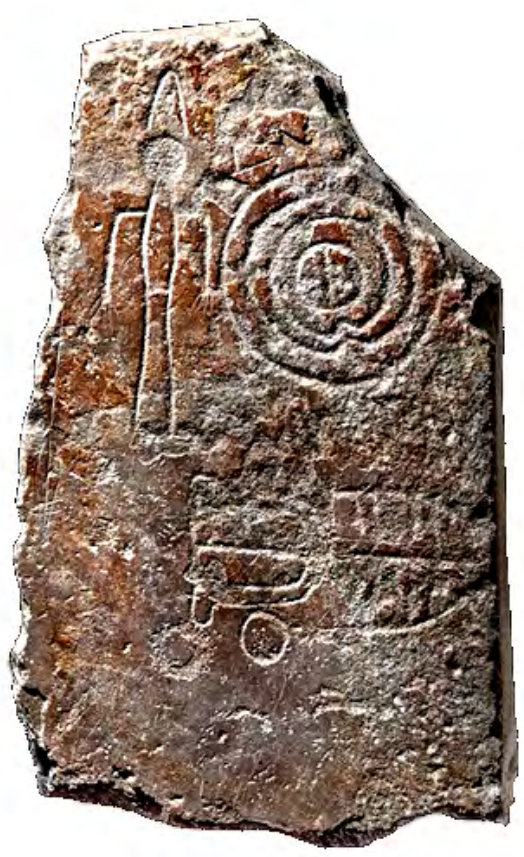

Fig 3. Estela de Las Herencias, Toledo. 
Es de esperar también que nuevos hallazgos de estelas en contextos arqueológicos definidos y precisos contribuyan a arrojar algo más de luz sobre su cronología, pues, como hemos visto $(\$ 1.2)$, no podemos estar totalmente seguros del momento en que empieza a desarrollarse este tipo de epigrafía. También es de desear que podamos contar con datos arqueológicos que nos permitan establecer una cronología relativa de las estelas que no se base únicamente en criterios estilísticos y paleográficos de supuesta evolución, sino en datos arqueológicos externos. Correia 1996, 53-62, ya intentó establecer una serie de grupos de inscripciones más antiguas y más recientes en relación también con la propia evolución de la escritura; sin embargo, dicha clasificación y, sobre todo, las cronologías propuestas, deben revisarse en función de la cronología general de las estelas del SO.

También mencionábamos más arriba $(\$ 1.5)$ los problemas relativos a la delimitación del corpus epigráfico de la escritura del SO. Hasta ahora signario, uso redundante de los signos vocálicos y tipo epigráfico (estela funeraria) iban unidos. Como ya hemos visto, tenemos que empezar a admitir la existencia de tipos epigráficos diferentes. $Y$, además, cabe que nos cuestionemos si, en realidad, la redundancia es una característica fundamentalmente relacionada con el tipo de soporte y su función o, incluso, una variante ortográfica que no tiene por qué aparecer en otras inscripciones en las que se utilizan los mismos signos o muy parecidos, pero sin redundancia vocálica. Estos problemas llevaron a Untermann a limitar las inscripciones recogidas en su área $\mathrm{J}$ a las que son propiamente estelas funerarias en escritura del SO con redundancia vocálica (más el signario de Espanca) y a relegar a la introducción ( $M L H$ IV, 97-113) algunas inscripciones como las de Azinhal, Ourique (MLH IV, 97-98) o Cañamero, Logrosán (MLH IV, 112), por citar tan solo un par de ejemplos. En este sentido, hay que plantearse la relación que guardan con las inscripciones del SO grafitos cerámicos como los de Abul en Alcácer do Sal (Correa 2011, 104-107) o Moura (Guerra 2013, 329-331), así como la controvertida leyenda monetal de la ceca de Salacia (MLH I A.303, MLH IV 110-111, García-Bellido y Blázquez 1995, s. u. Salacia, BDH Mon.103), que muchos autores consideran una pervivencia de la escritura del SO hasta época romana, así como el propio signario de Espanca, que para Javier de Hoz no está tan próximo a la escritura del SO como a un sistema más relacionado con el meridional (De Hoz 2010, 522-524).

Toda esta cuestión, además, tiene derivadas más amplias, pues en los últimos años hemos ido tomando conciencia de la existencia de un número cada 
vez mayor de variedades de escrituras paleohispánicas en el sur de la península ibérica, cuyas relaciones históricas distan aún mucho de estar claras. En los próximos años, por tanto, la investigación tendrá que plantearse de forma global las relaciones entre esas distintas variedades de escritura, diferentes entre sí pero al mismo tiempo claramente relacionadas, y todo ello en relación también con el origen de las escrituras paleohispánicas. ${ }^{52}$

\subsection{Perspectivas de estudio futuras sobre la escritura del SO}

Dado que existen aún algunos signos de la escritura cuyo valor no es seguro, es una prioridad básica continuar con la investigación en este terreno para intentar acabar de determinar los valores de todos los signos de la escritura del SO. Para ello dependemos de los nuevos hallazgos que puedan producirse en los años venideros y añadan nuevas secuencias a las ya conocidas, al tiempo que hagan aumentar la frecuencia de los signos raros.

Pero a esto debemos añadir sin duda el desarrollo de metodologías y estudios combinatorios más precisos y exhaustivos. En este sentido, cabe destacar que una línea muy adecuada de estudio ha sido la que ha puesto en práctica Ferrer 2016, quien ha estudiado de forma sistemática qué signos vocálicos aparecen tras qué otros signos, lo que, teniendo en cuenta la aludida redundancia vocálica de esta escritura $(\$ 1.6)$, permite contribuir a precisar y/o garantizar los valores propuestos para los signos. Sus conclusiones quedaron recogidas en una tabla que reproducimos aquí como tabla 2. Como se ve en ella, las combinaciones de signos silábicos más signo vocálico redundante apuntan a que habría más de tres series de consonantes oclusivas, lo que, además, tiene una repercusión para la comprensión de la fonología de la lengua, ya que indicaría que en su sistema fonológico tenemos que contar con una cuarta serie, además de la labial, dental y velar.

52 Para una visión global actualizada de todos estos problemas, con referencias a los trabajos anteriores, puede consultarse el trabajo de Ferrer y Moncunill 2019, 93-104 y 105-107. 


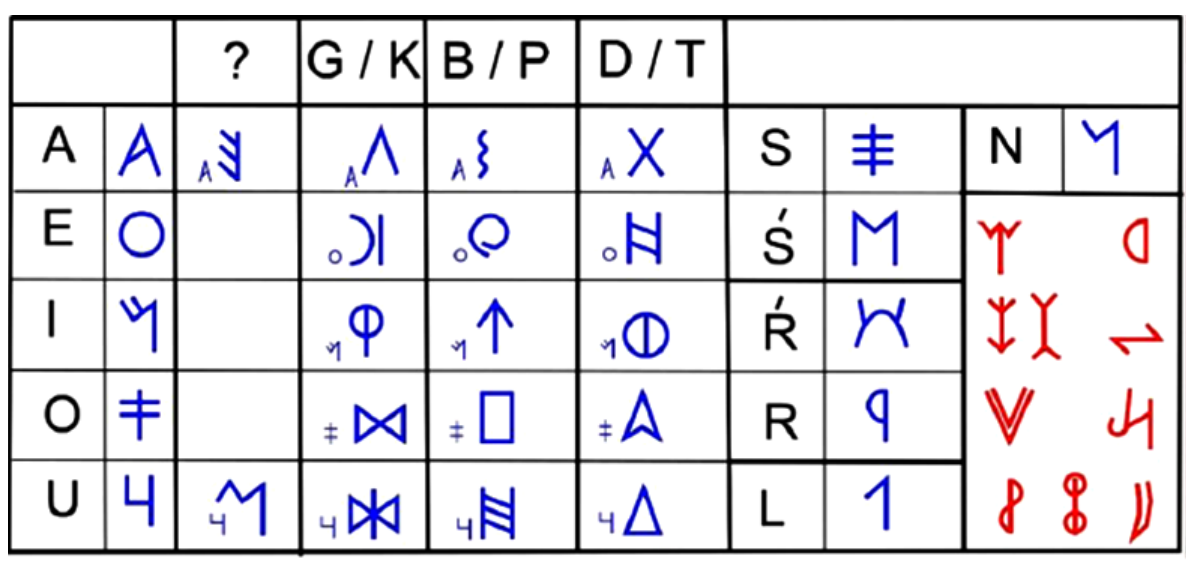

Tabla 2. Valores de los signos de la escritura del SO según Ferrer 2016 (en el campo inferior derecho los signos pocos frecuentes de valor fonético muy dudoso).

A la inversa, también el estudio de hechos de fonética tiene repercusión sobre la determinación de los valores de los signos de la escritura. Aludíamos un poco más arriba $(\$ 2.1)$ a las secuencias de dos signos vocálicos iguales y sus contextos fonéticos. Pues bien, en relación con la discusión sobre el valor fonético del signo de cuernos S56, considerado una segunda vibrante ŕ por la mayor parte de los autores, pero de valor incierto para De Hoz, la constatación mencionada más arriba de que las secuencias vocálicas dobles aa, oo y uu se dan generalmente ante lateral y vibrantes (Luján e. p.) sería un argumento para pensar que ese signo de cuernos representa realmente una vibrante (o, en todo caso, una lateral).

Por mencionar también otra línea de trabajo en la que vemos posibilidades de desarrollos futuros y en conexión con lo que veíamos al final de $\$ 2.2$, no con todos los signos silábicos existe una sistematicidad total en el uso de la redundancia vocálica, es decir, que se documentan con frecuencia casos en los que a un signo silábico no le sigue la misma vocal que incluye el signo. De $\mathrm{Hoz}$ 2010, 507-512, ha intentado ofrecer propuestas explicativas sobre el origen de esta práctica y tenemos ahora datos exhaustivos sobre esto gracias al trabajo de Ferrer 2016, lo cual puede tener implicaciones no solo para comprender el desarrollo de la propia escritura del SO, sino para el estudio del origen de las escrituras paleohispánicas como adaptación de la escritura fenicia. 


\subsection{Problemas de edición de las inscripciones del SO}

Como ya hemos indicado, existen diferentes formas de transcripción de la escritura del SO, más allá de la falta de acuerdo sobre el valor de algunos signos ( $\$ 1.6)$. Estas divergencias se refieren, en primer lugar, a la forma de reflejar en las transcripciones la redundancia vocálica. Cabe simplemente escribir la transcripción del signo silábico más la vocal redundante sin más, es decir, taa; poner la vocal entre paréntesis: $\mathbf{t}(\mathbf{a}) \mathbf{a}$; escribir la vocal únicamente una vez: ta; ${ }^{53}$ o bien, volar la vocal del signo silábico: $\mathbf{t}^{\mathbf{a}} \mathbf{a} \cdot{ }^{54}$ Últimamente parece que se está generalizando la utilización de la trasliteración con vocal volada, por la que abogamos, pues de esta manera al lector no especializado se le está llamando la atención sobre el hecho de que existe una particularidad en esta escritura en cuanto al uso de los signos silábicos que combinan una consonante oclusiva y una vocal. Y, por otro lado, dado que las vocales voladas no se utilizan para la transcripción de ningún otro signario paleohispánico, el investigador especializado puede identificar rápidamente a qué sistema de escritura pertenece una secuencia determinada que se cita en un trabajo de investigación.

Pero no acaban aquí los problemas de transcripción. Como señalábamos más arriba ( $\$ 1.6)$, la escritura del $S O$ no diferencia oclusivas sordas de sonoras, por lo que hay que tomar la decisión de con qué serie (sorda o sonora) se transcriben convencionalmente los signos. Tradicionalmente se habían utilizado transcripciones con la labial sonora $\left(\mathbf{b}^{\mathrm{a}}\right.$, etc.), la dental sorda $\left(\mathbf{t}^{\mathrm{a}}\right.$, etc.) y la velar sorda $\left(\mathbf{k}^{\mathbf{a}}\right.$, etc. $),{ }^{55}$ trasladando sin más el modelo derivado del sistema fonológico del ibérico y del celtibérico. Sin embargo, dado que no tenemos razones para pensar que, si en la lengua de las estelas del SO había oposición de sonoridad en las velares y las dentales, no la hubiera también en las labiales o, si no la había en las labiales, que no la hubiera tampoco en las dentales y velares, resultaría más adecuado utilizar sistemáticamente la transcripción también con labial sorda, es decir, transcribir $\mathbf{p}^{\mathrm{a}}, \mathbf{p}^{\mathrm{e}}, \mathbf{p}^{\mathrm{i}}$, etc. ${ }^{56}$

Resta también el problema de qué hacer con los signos de interpretación dudosa para evitar que las transcripciones que los incluyen sean tomadas por

53 Como hace Rodríguez Ramos 2002; 2015.

54 Tal y como hacen Correa (por ejemplo, Correa 1996 y Correa y Guerra 2019) y Untermann $M L H$ IV.

55 Así, Untermann, $M L H$ IV, passim.

$56 \mathrm{Al}$ modo de De Hoz 2010, entre otros. 
seguras por los lectores no especializados. De Hoz en sus trabajos recurre habitualmente a transcripciones con letras latinas mayúsculas que recuerdan la forma de los signos, por ejemplo, W para el signo con cuernos (S56) que otros autores trascriben como ŕ, o $\mathbf{E}$ para el signo en forma de $e$ invertida cuyo valor fonético no es seguro. Hay que reconocer que es difícil llegar a una trasliteración normalizada de la escritura en tanto subsistan tales problemas de identificación de algunos de los signos.

Finalmente, por lo que se refiere a la publicación del corpus de estas inscripciones, confiamos en que culminará en un plazo breve de tiempo la edición actualizada en el Banco de Datos Hesperia de las estelas del SO y de todas las inscripciones del área meridional de la península ibérica. En los más de veinte años transcurridos desde la publicación del volumen IV de los $M L H$ ha habido nuevos e interesantes hallazgos, entre ellos el del texto más largo actualmente conocido en escritura del SO, el de Mesas do Castelinho, ya mencionado. La existencia de un corpus online actualizado puede ayudar a continuar con el trabajo para progresar en nuestra comprensión de la lengua de las estelas del SO, así como en la determinación de las relaciones entre la escritura del SO y otras variedades de escrituras paleohispánicas del área meridional de la península ibérica.

\section{Agradecimientos}

Quiero dejar constancia del agradecimiento a los revisores anónimos de la revista Palaeohispanica por sus indicaciones que han contribuido a mejorar el trabajo.

\section{$\begin{array}{llllllllllll}\mathbf{B} & \mathbf{I} & \mathbf{B} & \mathbf{L} & \mathbf{I} & \mathbf{O} & \mathbf{G} & \mathbf{R} & \mathbf{A} & \mathbf{F} & \mathbf{I} & \mathbf{A}\end{array}$}

Beirâo 1986: C. de Mello Beirâo, Une civilization proto-historique du Sud de Portugal, vol. 3, París 1986.

Correa 1981: J. A. Correa, “Nota a la inscripción tartesia GM II”, AEspA 54, 1981, 203-209.

Correa 1985: J. A. Correa, “Consideraciones sobre las inscripciones tartesias”, en: J. de Hoz (ed.), Actas del III Coloquio sobre Lenguas y Culturas Paleohispánicas (Lisboa 1980), Salamanca 1985, 377-395.

Correa 1987: J. A. Correa, "El signario tartesio", en: J. Gorrochategui, J. L. Melena y J. Santos (eds.), Studia Palaeohispanica. Actas del IV Coloquio sobre Lenguas y Culturas Paleohispánicas [= Veleia 2-3], Vitoria 1987, 275-284.

Correa 1989a: J. A. Correa, "Posibles antropónimos en escritura del SO. (o tartesia)", Veleia 6, $1989,243-252$. 
Eugenio R. Luján

Correa 1989b: J. A. Correa, “El origen de la escritura paleohispánica”, en: Estudios sobre Urso, Sevilla 1989, 281-301.

Correa 1993: J. A. Correa, "El signario de Espanca (Castro Verde) y la escritura tartessia", en: J. Untermann y F. Villar (eds.), Lengua y Cultura en la Hispania Prerromana. Actas del V Coloquio sobre Lenguas y Culturas Prerromanas de la Península Ibérica, Salamanca 1993, 521-562.

Correa 1996: J. A. Correa, "La epigrafía del sudoeste: estado de la cuestión", en: F. Villar y J. D’Encanaçao (eds.), La Hispania Perromana. Actas del VI Coloquio sobre Lenguas y Culturas Prerromanas de la Península Ibérica, Salamanca 1996, 65-76.

Correa 2002: J. A. Correa, “Crónica epigráfica del Sudoeste”, PalHisp 2, 2002, 407-409.

Correa 2004: J. A. Correa, “Crónica epigráfica del Sudoeste”, PalHisp 4, 2004, 283-284.

Correa 2005: J. A. Correa, "Escritura tartesia”, en: G. Carrasco y J. C. Oliva (eds.), Escrituras y lenguas del Mediterráneo en la Antigüedad, Cuenca 2005, 289-305.

Correa 2006: J. A. Correa, “Crónica epigráfica del Sudoeste”, PalHisp 6, 2006, 295-298.

Correa 2008: J. A. Correa, “Crónica epigráfica del Sudoeste IV”, PalHisp 8, 2008, 295.

Correa 2009: J. A. Correa, "Reflexiones sobre la lengua de las inscripciones en escritura del sudoeste o tartesia", PalHisp 9, 2009, 295-307.

Correa 2011: J. A. Correa, "La leyenda indígena de las monedas de Salacia y el grafito de Abul (Alcácer do Sal, Setúbal”, en: J. L. Cardoso y M. Almagro Gorbea (eds.), Lucius Cornelius Bocchus Escritor Lusitano da Idade de Preta da Literatura Latina, Lisboa-Madrid 2011, 103-112.

Correa 2016: J. A. Correa, “Crónica epigráfica del Sudoeste V”, PalHisp 16, 2016, 337-342.

Correa y Guerra 2019: J. A. Correa y A. Guerra, "The epigraphic and linguistic situation in the south-west of the Iberian Peninsula", en: A. G. Sinner y J. Velaza (eds.), Palaeohispanic Languages and Epigraphies, Oxford 2019, 109-137.

Correia 1996: V. H. Correia, A epigrafia da Idade do Ferro do Sudoeste da Península Ibérica, Oporto 1996.

Díaz Guardamino 2010: M. Díaz Guardamino, Las estelas decoradas en la Prehistoria de la península Ibérica [tesis doctoral de la Universidad Complutense de Madrid], Madrid 2010.

Faria, Soares y Soares 2014: A. M. de Faria, R. M. Soares y A. M. Soares, "Novo fragmento da inscriçâo em caracteres do Sudoeste proveniente da Folha do Ranjâo (Baleizâo, Beja)", RPA 17, 2014, 159-166.

Ferrer 2016: J. Ferrer i Jané, “Una aproximació quantitativa a l’análisi de l’escriptura del sudovest”, PalHisp 16, 2016, 39-79.

Ferrer y Moncunill 2019: J. Ferrer i Jané y N. Moncunill, “Palaeohispanic writing systems”, en: A. G. Sinner y J. Velaza (eds.), Palaeohispanic Languages and Epigraphies, Oxford 2019, 78-108.

García Bellido y Blázquez 1995: M. P. García Bellido y C. Blázquez Cerrato, Diccionario de cecas y pueblos hispánicos, 2 vols., Madrid 1995.

Gómez Moreno 1962: M. Gómez Moreno, La escritura bástulo-turdetana (primitiva hispánica), Madrid 1962.

Guerra 2002: A. Guerra, "Novos monumentos epigrafados com escrita do Sudoeste da vertente setentrional da Serra do Caldeirâo", RPA 5, 2002, 219-231.

Guerra 2009: A. Guerra, "Novidades no ámbito da epigrafia pré-romana do Sudoeste hispânico", PalHisp 9, 2009, 323-338. 
Guerra 2013: A. Guerra, "Algumas questôes sobre as escritas pré-romanas do Sudoeste hispânico", PalHisp 13, 2013, 323-345.

MLI: E. Hübner, Monumenta Linguae Ibericae, Berlín 1893.

De Hoz 1990: J. de Hoz, "El origen oriental de las antiguas escrituras hispanas y el desarrollo de la escritura del Algarve", Estudos Orientais 1, 1990, 219-246.

De Hoz 2001: J. de Hoz, "Hacia una tipología del ibérico”, en: F. Villar y M. P. Fernández Álvarez (eds.), Religión, lengua y cultura prerromanas de Hispania, Salamanca 2001, 335-362.

De Hoz 2010: J. de Hoz, Historia lingüística de la península Ibérica en la Antigüedad, vol. I, Madrid 2010.

De Hoz 2019: J. de Hoz, “The linguistic situation in the territory of Andalusia”, en: A. G. Sinner y J. Velaza (eds.), Palaeohispanic Languages and Epigraphies, Oxford 2019, 138-159.

Kaufman 2015: T. Kaufman, Notes on the Decipherment of Tartessian as Celtic (Journal of IndoEuropean Studies Monograph Series 62), Washington 2015.

Koch 2013: J. Koch, Tartessian. Celtic in the South-west at the Dawn of History (2. a ed. revisada), Aberystwyth 2013.

Luján, e. p.: "La lengua de las inscripciones del sudoeste: estado de la cuestión", PalHisp 21, en prensa.

Maluquer de Motes 1968: J. Maluquer de Motes, Epigrafía prelatina de la península Ibérica, Barcelona 1968.

MLH IV: J. Untermann, Monumenta Linguarum Hispanicarum, vol. IV Die tartessischen, keltiberischen und lusitanischen Inschriften, Wiesbaden 1987.

Neto et alii 2016: N. M. Neto, P. M. Rebelo, R. Avila, M. Rocha y J. Á. Zamora, "Uma inscriçâo lapidar fenícia em Lisboa", RPA 19, 2016, 123-128.

Rodríguez Ramos 1992: J. Rodríguez Ramos, Análisis de epigrafía sudlusitana [Tesis de licenciatura de la Universitat de Barcelona], Barcelona 1992.

Rodríguez Ramos 2000: J. Rodríguez Ramos, "La lectura de las inscripciones sudlusitanotartesias", Faventia 22, 2000, 21-48.

Rodríguez Ramos 2002: J. Rodríguez Ramos, "Las inscripciones sudlusitano-tartesias. Su función, lengua y contexto socio-económico", Complutum 13, 2002, 85-95.

Rodríguez Ramos 2015: J. Rodríguez Ramos, "De nuevo sobre la lectura de la escritura monumental tartesia o sudlusitana", Veleia 32, 2015, 125-150.

Schmoll 1961: U. Schmoll, Die sudlusitanischen Inschriften, Wiesbaden 1961.

Schulten 1940: A. Schulten, "Los tirsenos en España", Ampurias 2, 1940, 33-53.

Sinner y Velaza 2019: A. G. Sinner y J. Velaza (eds.), Palaeohispanic Languages and Epigraphies, Oxford 2019.

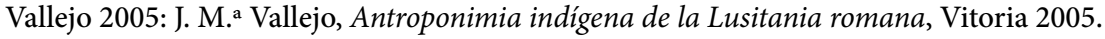

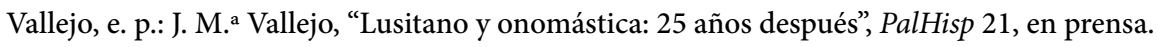

Zamora 2019: J. Á. Zamora, "Phoenician epigraphy in the Iberian peninsula", en: A. G. Sinner y J. Velaza (eds.), Palaeohispanic Languages and Epigraphies, Oxford 2019, 56-77. 